Original Research Paper

\title{
Determinants Factors of Agricultural Extension Services Performance and Impacts on Farmers' Behavior
}

\author{
${ }^{1}$ Muh. Hatta Jamil, ${ }^{2}$ Amri Jahi, ${ }^{1}$ Muhammad Arsyad, \\ ${ }^{3}$ Ma'mun Sarma, ${ }^{4}$ I. Gusti Putu Purnaba, ${ }^{1}$ Ni Made Viantika, \\ ${ }^{1}$ Rachmawaty A. Nadja, ${ }^{1}$ A. Nixia Tenriawaru and ${ }^{5}$ Mohamad Ikbal Bahua \\ ${ }^{I}$ Department of Socio-economics of Agriculture, Faculty of Agriculture, Hasanuddin University, Makassar, Indonesia \\ ${ }^{2}$ Department of Development Extension, Graduate School, Bogor Agricultural University, Bogor, Indonesia \\ ${ }^{3}$ Department of Management, Faculty of Economic and Management, Bogor Agricultural University West Java, Indonesia \\ ${ }^{4}$ Department of Statistics, Faculty of Mathematics and Natural Sciences, Bogor Agricultural University, West Java, Indonesia \\ ${ }^{5}$ Department of Agrotechnology, Faculty of Agriculture, Gorontalo State University, Gorontalo,, Indonesia
}

Article history

Received: 13-08-2016

Revised: 2-11-2016

Accepted: 25-11-2016

Corresponding Author:

Muh. Hatta Jamil

Department of Socio-

economics of Agriculture,

Faculty of Agriculture,

Hasanuddin University,

Makassar, Indonesia

Email: hattaj@yahoo.com

\begin{abstract}
Agricultural extension plays an important role in improving the quality of human resources, also it function as a learning process for the main actors so that farmer will be able to help and organize themselves in accessing market information, technology, capital and other resources. Problem that arise among stakeholders have been widely debated. Since then, determinant factor of Agricultural Extension Services (BPP) performance should be identified and how it will impact on farmers behaviour. There is a strong assumption that, BPP performance will affect agricultural development, but it is very difficult to determine by factors. The research objectives were to analyze determinants of BPP performance and impact on farmers behaviour. This research was conducted in South Sulawesi Province, Indonesia by selecting 109 BPP based on Slovin Method. The analysis analized with Structural Equation Modeling (SEM) using LISREL software. The results showed that development of BPP; management BPP, human resources, assisted farmers, resource of BPP, adaptation of BPP are positively affect Action Program of BPP. In addition, these determinants affect farmers behaviour in terms of farmers competency and participation through indirectly action program. This leads to argue that in order to improve farmers behaviour (improving competency and participation), it is needed to step up performance of BPP (making action program properly, in other words) through extension program improvement, groups activity plan and operational cost management.
\end{abstract}

Keywords: Agricultural Extension, Extension Center Performance, Action Program, Farmers Behaviors, Determinant of Performance

\section{Introduction}

Agricultural extension organizations have experienced "disorganization" while Indonesia entered the era of regional autonomy. Decentralization policy applied in several fields, including agriculture and the provision of agricultural extension services from the central government to the regions. Delegation of the implications on the organizational structure and nomenclature extension as for example is, Agricultural Extension
Services (BPP) changed the name of the agency agricultural information, branch offices agriculture department, Regional Technical Implementation Unit (UPTD), Sub-district Extension Center, Center for Agricultural and Forestry Extension, sub-offices, information office extension, part of the work unit in the department or agency and some have disbanded (extension pulled into service respectively) and the final shape of the Executive Agency of Agricultural Extension, Fisheries and Forestry (BP3K). Another 
implication, the resources needed, such as infrastructure and financing to carry out the task BPP organization in particular and agriculture in general education organizations increasingly inadequate for the operation of the organization BPP. Consequently BPP performance-related factors, which are not effective and efficient in describing the action program BPP. Therefore, extension system in the era of transition is quite complex, because it takes the ideal adjustment to the local conditions and characteristics of each region in Indonesia (Jamil, 2006). The statement is emphasized by Jamil (2009) and Knutson et al. (2004) that argues policy is the principle to direct actions of the members organization or government to achieve its objectives including Agricultural Extension Services (BPP) performance. As an organization, Leeuwis and Aarts (2011) pointed out that we need to think about communication as playing a role in innovation development. In addition, Information and Comunication Technologies (ICT) role for agricultural extension (Koehnen, 2011) needs to be considered, due to Farmers perceived that the use of different multimedia building blocks made it an interesting and educative tool (Shanthy and Thiagrajan, 2011) for extension center.

BPP in the district level is actually functioning as central point in extension organizational structure. It can be regarded as organizational implementation of the change, because BPP received the delegation of tasks from the central and provincial governments (Ministry of Agriculture and the Provincial Agriculture Office). In addition, they are also required to understand the problems and accommodate the aspirations of the bottom part (farmers) and in organizing extension on its territory. BPP performance is reflected in the formulation and elaboration and implementation of action programs related to the development of the BPP, BPP management, human resources of BPP, assisted (target) farmers, resource of BPP, BPP adaptation and action programs related to the behavior of farmers. Development of BPP performance will describe the organization has a performance that can sustain the role of its members in carrying out the duties and functions professionally. The hope will have an impact on the good performance of members of the organization and at the same time also affect the behavior of farmers. Where the action program is an effort to encourage farmers' behavior towards an increasingly competent and participative in the administration of counseling to aid farmers in farming in accordance with technological developments cultivation which it directly emphasized to the cultivation technology-based knowledge, tailored to the capabilities and attitudes of farmers locally in adopting agricultural technology, including (Meyer et al., 2002) job satisfaction, job involvement and occupational commitment. It will increase farmers welfare and so their families. It is really necessary to conduct the research on determinants of Agricultural Extension Services performance and its impact on farmers behavior. The research objectives are to analyze determinants of BPP performance and its impact on farmers attitudes.

\section{Materials and Methods}

This study was an analytical design is done based on the data ex post facto, as a form of research that analyze and assess the factual events that occurred on the field (Babbie, 1998; Nazir, 2003). The method used survey with questionnaire design and interview. The research was conducted in South Sulawesi Province, Indonesia by selecting 109 BPP based on Slovin Method (Sevilla et al., 1993). This study uses the validity of the framework (construct validity) to test the validity of measuring instruments/questionnaires used by setting the conceptual framework, then compiled benchmarks operational and set the indicators of each variable of the study, then performed a test expert, then field test instruments. Data were analyzed with the reliability test using Cronbach Alpha coefficients. The analysis employed Structural Equation Modeling (SEM) using LISREL software (Solimun, 2002; Wijanto, 2008).

\section{Results and Discussion}

\section{Test for Goodness of Fit}

The overall test persuasively resulted in the rejection of H0 that "there is no significant impact of the independent variables on the dependent ones" as a whole. This could be proved that all path coefficients in the Path Equation are zero. In addition, it can also be identified that the significance test for each path coefficient of the intermediate variables lead us to reject $\mathrm{H} 0$ that "there is no significant impact of the independent variables on the intermediate ones".

The regression results show the $\mathrm{R}^{2}$ of path equations on "Action Program $\left(X_{7}\right)$ " as a dependent variable in this step of analysis reached 0.61 . This figure tells us that $61.0 \%$ of the total variance of endogenous variable (Action Program) in general, can be explained by all explanatory (independent) variables. We may therefore state that the model constructed through their dimensions in the research is adequate enough in explaining the Performance of BPP.

\section{Identifying Determinants of BPP Performance}

It is important to note that after analyzing the variables that affect the action program as a 
representation of the performance of BPP, it was found that performance of BPP can be drawn as Fig. 1 and the path of influence between variables can be formulated as a structural model of the following equation:

$$
\begin{aligned}
& Y_{1}=0,21 X_{1}+0,53 X_{2} \\
& +0,23 X_{3}+0,17 X_{4}+0,54 X_{4}+0,15 X_{4}
\end{aligned}
$$

$Y_{2}=0,78 Y_{1}$

Where:

$X_{1}=$ Development of BPP

$X_{2}=$ Management of BPP

$X_{3}=$ Human resources of BPP
$X_{4}=$ Assisted (target) Farmers

$X_{5}=$ Resources of BPP

$X_{6}=$ Adaptation of BPP

$Y_{1}=$ Action Program

$Y_{2}=$ Farmers Behaviour

Figure 1 clearly depicted that development of BPP, management, human resources, assisted farmers, resources and BPP adaptation directly affect BPP action program with effect sequentially coefficient of 0.21 ; $0.53 ; 0.23 ; 0.17 ; 0.54 ; 0.15$ significant at $\alpha=0.05$. So mathematical equations structural model BPP action program as follows: $Y_{1}=0.21 X_{1}+0,53 X_{2}+0.23 X_{3}+$ $0.17 X_{4}+0.54 X_{5}+0.15 X_{6}$. Overally, these sixth variables influence the action program.

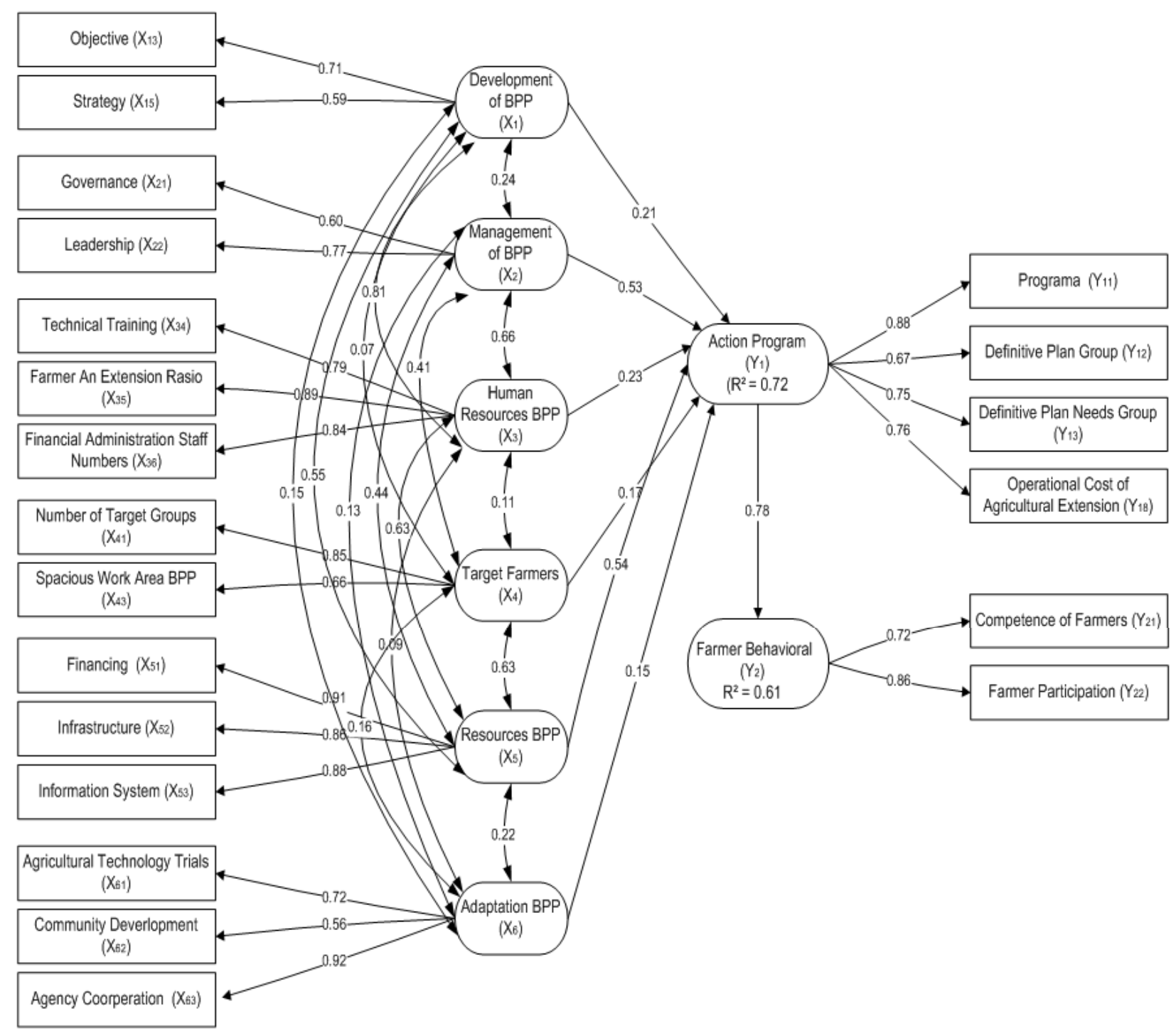

Fig. 1. Structural model of BPP performance Chi-Square $=189,57, \mathrm{df}=161, \mathrm{P}$-value $=0.06135, \mathrm{RMSEA}=0.053, \mathrm{CFI}=0.92$ 
Table 1. Direct and indirect effect of independent variables on farmers behaviour

\begin{tabular}{llll}
\hline & Effect coefficient & \\
& ----------- & \\
& Direct & Indirect & $t$ \\
\hline BPP Development & - & 0.14 & 2,56 \\
BPP Management & - & 0.16 & 2,38 \\
Human Resources & - & 0.43 & 4,45 \\
Assisted Farmers & - & 0.37 & 2,89 \\
BPP Resources & - & 0.49 & 4,48 \\
BPP Adaptation & - & 0.17 & 2,43 \\
Action Program & 0.78 & - & 2,89 \\
\hline
\end{tabular}

Table 1 shows the variables influence the development of BPP, management, human resources, assisted farmers, resource, BPP adaptation and action program on farmer behavior in sequence, namely: 0,14 ; $0.16 ; 0.43 ; 0.37 ; 0.49 ; 0.17$ and 0.78 real at $\alpha=0.05$. Development of BPP, the management of BPP, human resources, assisted farmers, resource BPP, adaptation BPP and program of action affect indirectly on the farmers behaviour, while the action program direct effect on farmers' behavior, so mathematical equations structural model the behavior of farmers is: $Y_{2}=0.78$ $Y_{1} ; Y_{2}$ is the behavior of farmers and $Y_{1}$ is action program. Figure 1 shows the effect of the action program variables on changes in farmer behavior in sequence, namely: $0.78 ; 0.56$; and 0.67 . Action program affect indirectly on the competence and participation of rice farmers, so mathematical equations structural model the behavior of rice farmers is: $Y_{1} Y_{2}=$ $0.78 ; Y_{2}$ is the behavior of rice farmers and $Y_{1}$ is a program of action. In Fig. 1 also shows that action program affect directly on the farmers behavior.

The results showed that the development of real BPP directly affect on action program. It gives the sense that the development of the BPP also determine the level of quality of action programs of BPP (with a coefficient of 0.21). Effect of program development can be seen in the quality of programming formulation of agricultural extension, quantity and quality in facilitating Group Definitive Plan (hereafter, RDK) and Group Needs Definitive Plan (hereafter, RDKK) and ability in managing operational costs as extension agents and BPP staff. The research also shows that management of BPP affect action program. This means that the BPP management determines action programs of BPP (coefficient of 0.53). The influence of BPP management on the action program can be identified on the ability of BPP in formulating program, facilitate RDK and RDKK, utilize Operational Cost of Agricultural Extension BOPP carefully and wisely to organize the learning process. This is line with Asian Development Bank that governance relies on four key elements: (1) Accountability, (2) participation, (3) predictability and (4) transparency. UNDP is also preparing elements of governance, namely:
(1) Participatory, (2) transparent, (3) accountable, (4) equitable and (5) promotes the rule of law.

This study showed that variables Human Resources (HR) significantly affect BPP action program. It gives the sense that the human resources also determine whether or not it's good action programs formulated and implemented (coefficient of 0.23). the influence of human resources on the action program can be recognized on the ability of BPP to formulate program, as well as the facilitation of RDK, RDKK, BOPP utilization efficiency in performing the duties and functions of BPP staff in the learning process that runs from the BPP. In line with these results, the position and function of $\mathrm{HR}$ in the organization is very strategic, because HR is the motor of other resources so that the organization is in keeping with the mission and objectives to be achieved. It was raised Kontoghiorghes et al. (2005). Furthermore, Russell and Taylor III (2003) also argued about SDM, where his position as staff/employees who have a need and a necessity for development, disclosed that the strategic issues on human resources include the determination of the level of skill and degree of autonomy necessary for the operation of the production system, outlines selection criteria of training needs and determine policy on performance evaluation, compensation and incentives.

Results of the study showed that the assisted farmers significantly affect BPP action program. It means that assisted farmers also determine how well the formulation and implementation of BPP action program (coefficient of 0.17 ). Influence of variables assisted farmers in the action program can be seen from the programming was formulated and used as a planning document for implementation, the ability of facilitating RDK and RDKK structured, well managed of operational costs and carrying out the learning process and other functional tasks. Effect of assisted farmers to the program of action, which is characterized by the large number of groups that are handled by BPP and covering area of BPP becomes Regional Work of Agricultural Extension Services (WKBPP). As Samsuddin (1987) pointed out that the role of farmer groups can be observed, that change the behavior of farmers through the activities of individuals, usually slower than if the farmer concerned is active in group activities. This is a reason why Jahi and Newcomb (1981) emphasized that extension is constantly changing.

In addition, the resource of BPP significantly affect BPP action program. This indicates BPP also determine the resources properly determined the action program (coefficient of 0.54). Influence of BPP resource on action program can be seen from a well determined the program, formulating and preparing RDK and RDKK, utilization of BOPP effectively and efficiently. In line with this study, the general concept of organizational 
performance based on the idea that the organization is a voluntary association of productive assets, including human, physical and capital resources, for the purpose of achieving common goals (Carton and Hofer, 2006). So also with what is raised by Carton and Hofer (2006) that they provide asset just to run their organizations as long as they are satisfied with the value they receive in exchange, relative to the use of alternative assets. Lusthaus et al. (2002) suggested that every organization should strive to meet the objectives by expenditure received from the resource while ensuring long-term sustainability. The study also depicted that the adaptation of BPP significantly affect action program of BPP. This means that adaptation also determine the abilitym of formulating a good action program (coefficient of 0.15 ). Effect of adaptation to the action program are shown on the ability BPP in increasing quality program formulation, facilitating and preparation of $\mathrm{RDK}$ and RDKK as well as the ability to take advantage of BOPP effectively and efficiently.

Another interesting finding of the study is the effect of the development of BPP, management of BPP, human resources, assisted farmers, resources and adaptation of BPP on farmers' behavior. These six variables send their effect indirectly to farmers behaviour through action program. This indicates that farmers behaviour can be improved through action program of BPP improvement. Meanwhile the action program variables $\left(Y_{1}\right)$ direct and significantly affect farmers behaviour. This convey an important message that in order to improve farmers behaviour, it is really need to stepping up action program of BPP. In line with these findings, Lionberger and Gwin (1991) suggested that agricultural extension activity is one of the causal factors of changing farmers' behaviour. Furthermore van den Ban and Hawkins (1999) argued that from extension viewpoint to change farmers behaviour by three importants efforts: (1) Education; (2) provide assistance and (3) compulsion "policy" (laws), indicating that the government should prioritize the revitalization of agricultural development (Arsyad, 2010) in terms of agricultural extension.

\section{Conclusion}

The results showed that development of BPP, management BPP, human resources, assisted farmers, resource of BPP, adaptation of BPP positively affect Action Program of BPP as performance proxy directly. In addition, these determinants affect farmers behaviour in terms of farmers competency and participation through action program though indirectly. This leads to argue that in order to improve farmers behaviour (improving competency and participation), it is needed to step up performance of BPP (making action program properly, in other words) through extension program improvement, groups activity plan and operational cost management.

\section{Acknowledgement}

Authors like to thanks to Professor Yoshio Kawamura, Senior Fellow in Agricultural/Rural Development Studies, Ryukoku University, Kyoto for his valuable discusion on earlier drafts of this paper, especially in employing Structural Equation Modeling. Special word of thanks to Ministry of Education and Culture, Republic of Indonesia for providing Research Grant.

\section{Funding Information}

This research was funded by Ministry of Education and Culture, Republic of Indonesia for Research Grant, during 2015-2016 period.

\section{Author's Contributions}

Muh. Hatta Jamil: $\mathrm{He}$ is principal author and responsible for all research steps, controlling questionnaire, analyses, from field survey for collecting data, computing and screening data until the end of analysis.

Amri Jahi: He undertook all linkages between field survey and Agricultural Extension Service (BPP) to get data needed, as well as model re-specification before constructing questionnaire.

Muhammad Arsyad: He undertook all interpretation, indication and synthesizes some possible policies implication. In addition, he also emphasized direct and indirect effects of independent variables on farmers' behavior in the analysis.

Ma'mun Sarma: He had a strong contribution in defining concept, selecting site and cleaning variables for the analysis.

I Gusti Putu Purnaba: He contributed to develop Structural Equation, Model Re-specification and extracting farmers behavior into dimension/concept

Ni Made Viantika: She had a significant contribution in structuring issues on the paper, controlling abstract as well as in adjusting the paper template

Rachmawaty A. Nadja: She organized field works with enumerator, pre-test questionnaire and doing full survey by selecting research site and re-adjusting questionnaire based on pre-test results.

A. Nixia Tenriawaru: She contributed to extract Test Goodness of fit of the model specified (including detected the most important impact of the variable), enable to extract findings indication.

Mohamad Ikbal Bahua: He strengthen consistency of manuscript by controlling strictly the objectives, method, messages of principal findings and conclusion. 


\section{Ethics}

Authors declare that no ethical problems expected after publishing this paper.

\section{References}

Arsyad, M., 2010. The dynamics of cocoa smallholders in Indonesia: An application of path analysis for poverty reduction. Bull. Indonesian Econom. Stud., 46: 251-254.

Babbie, E., 1998. The Practice of Social Research. 8th Edn., Wadsworth Publishing Company, Belmont, Ca, ISBN-10: 053450468X, pp: 465.

Carton, R.B. and C.W. Hofer, 2006. Measuring Organizational Performance: Metrics for Entrepreneurship and Strategic Management Research. 1st Edn., Edward Elgar Publishing, Cheltenham, ISBN-10: 1847202845, pp: 276.

Jahi, A. and L.H. Newcomb, 1981. Orientation: Adjust for agent characteristic. J. Extens., 25: 23-27.

Jamil, M.H., 2006. Agricultural extension system in indonesian: Enhancement of extension systems in agriculture. APO, Tokyo.

Jamil, M.H., 2009. Agricultural policy: Challenging and prospect. Proceedings of the International Roundtable Discussion, (IRD'09), Universiti Putra Malaysia, Malaysia.

Knutson, R.D., J.B. Penn, B.L. Flinchbaugh and J.L. Outlaw, 2004. Agricultural and Food Policy. 6th Edn., Pearson, Prentice Hall, New Jersey Columbus, Ohio.

Koehnen, T.L., 2011. ICTs for agricultural extension. global experiments, innovations and experiences. J. Agric. Educ. Extens., 17: 473-474. DOI: 10.1080/1389224X.2011.624714

Kontoghiorghes, C., S.M. Awbrey and P.L. Feurig, 2005. Examining the relationship between learning organization characteristics and change adaptation, innovation and organizational performance. J. Hum. Resource Dev. Q., 16: 185-212.

DOI: $10.1002 / \mathrm{hrdq} .1133$
Leeuwis, C. and N. Aarts, 2011. Rethinking communication in innovation processes: Creating space for change in complex systems. J. Agric. Educ. Extens., 17: 21-36. DOI: $10.1080 / 1389224 X .2011 .536344$

Lionberger, H.F. and P.H. Gwin, 1991. Technology transfer: From researchers to user. University of Missouri.

Lusthaus, C., M.H. Adrien, G. Anderson, F. Carden and G.P. Montalvan, 2002. Organizational Assessment: A Framework for Improving Performance. IDRC, Washington, DC, ISBN-10: 0889369984, pp: 202.

Meyer, J.P., D.J. Stanley, L. Herscovitch and L. Topolnytsky, 2002. Affective, continuance and normative commitment to the organization: A metaanalysis of antecedents, correlates and consequences. J. Vocat. Behav., 61: 20-52. DOI: $10.1006 /$ jvbe. 2001.1842

Nazir, M., 2003. Research methods. Publisher Ghalia Indonesia, Jakarta.

Russel, R.S. and B.W. Taylor III, 2003. Operations Management. 4th Edn., Prentice Hall, New Jersey.

Samsuddin, U., 1987. Extension Basics and Agriculture Modernization. Bina Cipta, Bandung.

Sevilla, C.G., J.A. Ochave, T.G. Punsalan, B.P. Regala and G.G. Uriarte, 1993. Introduction Research Methods. UI Press, Jakarta.

Shanthy, T.R.. and R. Thiagrajan, 2011. Interactive multimedia instruction versus traditional training programmes: Analysis of their effectiveness and perception. J. Agric. Educ. Extens., 17: 459-472. DOI: $10.1080 / 1389224 X .2011 .596708$

Solimun, 2002. Structural Equation Modeling (SEM); Lisrel and Amos. Malang: Publisher Malang University.

van den Ban, A.W. and H.S. Hawkins, 1999. Agricultural Extension. Publisher Kanisius, Yogyakarta.

Wijanto, S.H., 2008. Structural Equation Modeling with Lisrel 8.8: Concept and Tutorial. Publisher Graha Ilmu, Yogyakarta. 